\title{
Bus Voltage Stabilization Control of Photovoltaic DC Microgrid Based on Fuzzy-PI Dual-Mode Controller
}

\author{
Yu Zhang $\mathbb{D}^{1,2,3}$ Shuhao Wei, ${ }^{1}$ Jin Wang, ${ }^{1}$ and Lieping Zhang $\mathbb{D}^{1}$ \\ ${ }^{1}$ The College of Mechanical and Control Engineering, Guilin University of Technology, Guilin 541004, China \\ ${ }^{2}$ Guangxi Key Laboratory of Building New Energy and Energy Saving, Guilin 541004, China \\ ${ }^{3}$ The College of Electrical Engineering, Guangxi University, Nanning 530004, China \\ Correspondence should be addressed to Lieping Zhang; zlp_gx_gl@163.com
}

Received 29 February 2020; Revised 26 June 2020; Accepted 13 July 2020; Published 5 August 2020

Guest Editor: Mauro de Souza Tonelli-Neto

Copyright ( $\odot 2020 \mathrm{Yu}$ Zhang et al. This is an open access article distributed under the Creative Commons Attribution License, which permits unrestricted use, distribution, and reproduction in any medium, provided the original work is properly cited.

The photovoltaic DC microgrid has strong nonlinearity and time variation. Therefore, traditional dual closed-loop control strategy of voltage and current based on PI controller cannot effectively restrain the fluctuation and impact of DC bus voltage when the dynamic response of the system is improved. Under this situation, in this paper, the fuzzy-PI dual-mode controller is designed to upgrade the traditional dual closed-loop control, taking voltage outer ring into consideration, which is adopted to achieve good transient performance while the bus voltage deviation is large. While the bus voltage deviation is small, the PI controller is utilized for good steady-state performance. Hence, simulation and experimental results show that the fuzzy-PI dual-mode controller has the same advantages with both fuzzy control and PI control; in other words, it has the features of speedy response, low overshoot, good robustness, and strong anti-interference under different working conditions.

\section{Introduction}

In terms of the photovoltaic DC microgrid system, the bus voltage is the only standard to measure the systematic security and stability $[1,2]$. However, as affected by the randomness and fluctuation of the power of photovoltaic power generation as well as the dynamic change of load, there is an unpredictable power disturbance of the PV DC microgrid in the practical function, bringing large fluctuation into the bus voltage. Therefore, how to maintain the stable operation of the DC bus voltage and how to ensure the quality of power are crucial problems to be solved urgently [3]. Currently, compensation is made through energy storage device (ESD) that is incorporated into the DC bus through the bidirectional DC/DC converter (BDC) [4]. The micropower source is able to supply energy and the load can store energy, relying on the amount of the bus voltage, so as to strengthen the systematic robustness [5-10].

At present, the converter of energy storage unit generally adopts the strategy of dual closed-loop control of voltage and current or its upgraded strategy. Furthermore, traditional dual closed-loop control of voltage and current, with taking the bus voltage as the control outer ring and energy-storing inductive and current as the control inner ring, makes compensation by the PI controller under the classical control theory $[11,12]$. This traditional control fails to effectively restrain the large fluctuation and impact of the DC bus voltage while improving the systematic dynamic response.

According to this problem, a great number of scholars introduce the method of feedforward control into the traditional dual closed-loop control [13, 14]. And these methods can be divided into current feedforward and power feedforward according to different variables of the feedforward. For example, Takei et al. put forward three methods for testing feedforward control of load current aiming at unstable zero point of Boost converter, which, compared with the feedback control, successfully restrained the voltage's change and enhanced systematic stability when reducing the output filter capacitance [15]. In addition, Hou et al. fed forward the load current to the control link based on direct power control. And experimental results and simulations showed that the load current feedforward 
scheme significantly intensified the dynamic response of DC converters and kept the constant of output voltage under load's abrupt change [16]. Besides, Lu et al., based on the DC/DC buck converter, brought in ripple compensation link established by load current feedforward in the current inner ring control, so as to speed up the dynamic response speed of the inner ring and perfect the quality of the systematic output power [17]. The above current feedforward control strategy enhances the dynamic response performance of the system to some extent. But due to the delay of the voltage ring and current ring, the output current response will lag behind the load disturbance.

The power feedforward is similar to the current feedforward control, and it feeds forward the disturbance power to the control link to suppress the fluctuation of the bus voltage [18]. For example, Zhi-Lin et al., taking the fluctuation problem of the DC bus caused by the mismatch between output power and load consumption of renewable energy for the DC microgrid into consideration, raised the control method of power feedforward compensation based on the classical dual closed-loop control to lead power disturbance into controller through the feedforward channel, so as to restrain the fluctuation of the bus voltage and reinforce systematic stability [19]. Moreover, Song and Zhu, in order to elevate the antiload disturbance ability of the bidirectional DC/DC converter, came up with the strategy of virtual direct power control on the basis of direct power feedforward control which did not need to consider the parameters of converter's energy storage inductance and transformer's changing ratio and boosted systematic compatibility [20]. More importantly, the power feedforward accelerates the response speed of the system to power disturbance, which, to a certain degree, improves the system's ability to restrain the fluctuation of the bus voltage. However, similar to the current feedforward, the power feedforward needs going through the current inner ring as well, from which the output current still has certain delay compared with the load disturbance. Meanwhile, it should be noted that the feedforward control requires to simultaneously collect the real-time information of systematic parameters and increases the cost of the system while reducing its reliability at the same time, which is not conducive to the expansion of the microgrid and the popularization of plug-and-play functions. In view of the problems in the feedforward control, Ibrahim et al. introduce the methods of state observer, nonlinear perturbation observer into the control loop. When the state observer estimates the amount of disturbance, it is not necessary to establish an accurate mathematical model including the disturbance signal $[21,22]$. As the models' construction is relatively simple, a great deal of mathematical calculation is avoided to meet the requirements of system's real-time property, whereas noises are inevitably introduced and affect the power quality of the microgrid at the time when the observer is used to observe the state variables of the system.

In terms of the strong nonlinearity and time variability of the photovoltaic DC microgrid [23-27], fuzzy-PI dual-mode controller upgrades the traditional dual closed-loop control in this paper. And for the voltage outer ring, the fuzzy controller is adopted to obtain good transient performance when the deviation of the bus voltage is large. On the contrary, the PI controller is adopted to get good steady-state performance when the deviation of the bus voltage is small. The simulation and experimental results show that the fuzzy-PI dual-mode controller, boosting the advantages of the fuzzy control and the PI control, enjoys fast response speed, low overshoot, good robustness, and strong antijamming ability under different working conditions.

\section{Topology Structure and Circuit Structure Diagram of the Photovoltaic DC Microgrid}

2.1. Topology Structure of the Photovoltaic DC Microgrid. The topology structure of the photovoltaic DC microgrid is shown in Figure 1, and it is mainly composed of photovoltaic arrays, batteries, loads, and various types of energy conversion devices, among which the photovoltaic arrays and batteries are connected to the DC bus by the Boost and BDC, respectively, and the loads include resistive load and constant power load. For the two loads, the first one is directly parallel connection to the DC bus, and the other one is connected to the DC bus through the Buck converter, which is equivalent to the constant power load together with the Buck converter. As the photovoltaic DC microgrid can work in grid-connected and off-grid working mode, this paper mainly takes the bus voltage stabilization of the photovoltaic DC microgrid when off-grid functions.

2.2. Circuit Diagram of the Photovoltaic DC Microgrid. The main circuit construction of the photovoltaic DC microgrid during the off-grid operation is shown in Figure 2. In this figure, $L_{\mathrm{pv}}, L_{\mathrm{bat}}$, and $L_{1}$ represents the energy storage inductance $(H)$ of the Boost converter, the bidirectional DC/ DC converter, and the Buck converter respectively; $i_{\mathrm{pv} \_\mathrm{dc}}$ serves as the output current for the Boost converter, and $i_{\mathrm{b}} \mathrm{dc}$ shows the output current that bidirectional DC/DC converter is connected behind the battery, which has bidirection; $i_{\text {load }}$ represents the current of the Buck converter; $i_{R}$ is the current of the resistive load; $C_{\mathrm{dc}}$ refers to the capacitance of the DC bus; and $u_{\mathrm{dc}}$ indicates the voltage of the DC bus.

If the battery modules are not considered, according to the current equation by Kirchhoff, the dynamic equation for the DC bus is

$$
C_{\mathrm{dc}} \frac{\mathrm{d} u_{\mathrm{dc}}}{\mathrm{d} t}=i_{\mathrm{pv} \_\mathrm{dc}}-i_{\text {load }}-i_{R}
$$

From formula (1), the DC bus voltage is influenced by output current as well as load current of the photovoltaic modules. And when photovoltaic output is equal to load consumption, the voltage of the DC bus is stable, but it is affected by the randomness and volatility of the photovoltaic output and the dynamic change of the load. Hence, it is difficult to ensure that the output current is exactly the same as the input current of the load of the Boost converters within all periods. After adding battery modules, the dynamic equation for the DC bus is 


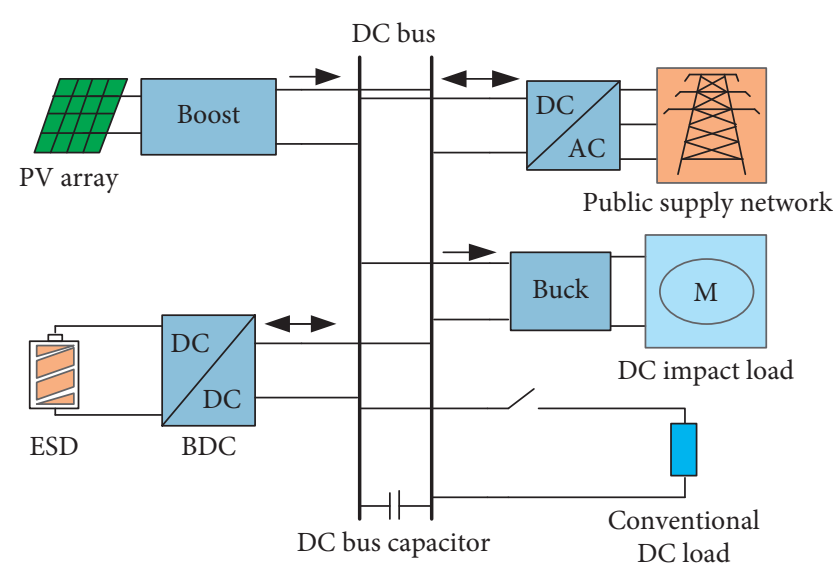

Figure 1: Topology structure of the photovoltaic microgrid.

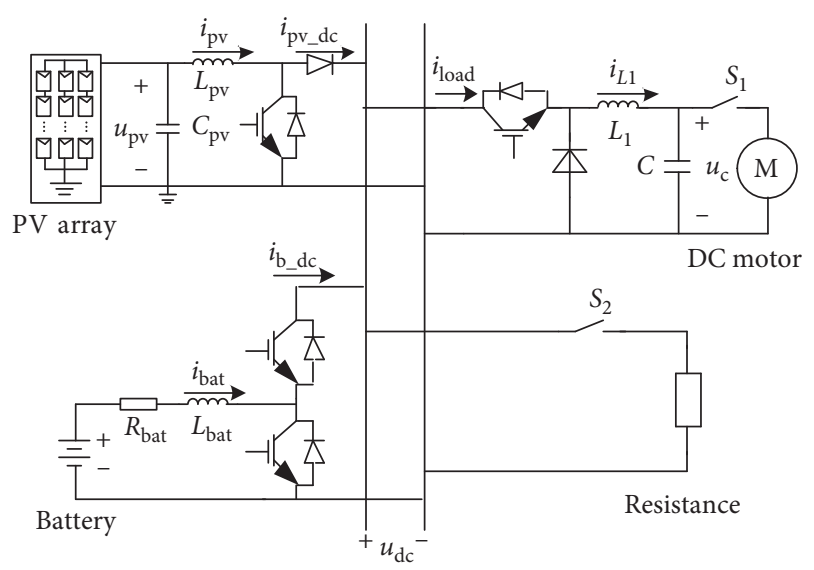

Figure 2: Circuit structure of the photovoltaic DC microgrid.

$$
C_{\mathrm{dc}} \frac{\mathrm{d} u_{\mathrm{dc}}}{\mathrm{d} t}=i_{\mathrm{pv} \_\mathrm{dc}} \pm i_{\mathrm{b} \_\mathrm{dc}}-i_{\text {load }}-i_{R} .
$$

When $i_{\mathrm{b} \_\mathrm{dc}}$ is expressed as " + ," it shows that the battery discharges, providing energy for the system. When $i_{\mathrm{b} \_\mathrm{dc}}$ is expressed as "-," it shows that the battery charges, absorbing system's surplus energy. The system is guaranteed to function safely and stably through controlling the charge and discharge of the battery to restrain the fluctuation of DC bus voltage.

\section{Fuzzy-PI Dual-Mode Controller}

The classical PI controller not only has simple and strongly stable algorithm, but also has simple and effective control effects for precise linear system of mathematical models. However, the distributed power source is of diverse categories, the running states, the output characteristics, and the control methods, belonging to the typical nonlinear system in the microgrid. When systematic workload is large, especially in the case of largely sudden change of load or access to impact load, the robustness of microgrid system based on the PI control is less weak, which is difficult to suppress the impacts of system's high-power disturbance on the DC bus voltage in a short time. The fuzzy control serves as a kind of intelligent control algorithm based on fuzzy set theory, fuzzy language variables, and fuzzy logic reasoning. Importantly, it transforms natural language into control strategy not relying on the system's precise mathematical models. Furthermore, its great robustness is suitable to solve the problems of nonlinearity, strong coupling time variation, and lag in the control process, and it is an important method for human beings to tackle complicated nonlinear systems, while the fuzzy control lacks the integral link, which is difficult to eliminate and leads to the reduction of the controlled accuracy and the dynamic quality of the system.

In order to effectively cope with the contradiction of the dual closed-loop control based on the PI in improving the steady accuracy and dynamic performance of the system, this paper proposes a PI controller that the fuzzy-PI dualmode controller replaces the voltage outer ring with combining the advantages of the fuzzy controller and PI controller. If the system's deviation is large, the fuzzy control scheme is selected to enhance the mediation range. If the error is small, the PI control scheme is chosen to elevate the steady-state accuracy. The control frame is shown in Figure 3.

In Figure 3, $U_{\mathrm{dc}}^{*}$ and $i_{\mathrm{bat}}^{*}$ are the given values of the voltage outer ring and the current inner ring, respectively; $U_{\mathrm{dc}}$ and $i_{\mathrm{bat}}$ are the sampling values of the voltage of the DC bus and the current of energy-storing inductance, respectively. In addition, the current inner ring adopts the PI controller, and the voltage outer ring applies the fuzzy-PI dual-mode controller, which chooses different controlling strategies according to the deviation of the bus voltage. Since application of the PI controller is so mature, the fuzzy controller and mode selector are primarily described as follows.

3.1. Fuzzy Controller. The fuzzy controller is also called fuzzy logic controller. Because the adopted fuzzy control rules are described by fuzzy conditional statements of fuzzy theory, the fuzzy controller is a language controller, also known as fuzzy language controller. This paper employs a two-dimensional fuzzy controller, and the system's frame is shown in Figure 4.

In Figure 4, $e$ and ec are the input of the fuzzy control, where $e$ represents the systematic deviation; ec acts as the deviation's changing rate $\mathrm{ec}=\mathrm{d} e / \mathrm{d} t ; u$ is the amount of output control; $k_{e}$ and $k_{\mathrm{ec}}$ as well as $k_{u}$ are the quantitative factors of $e$, ec, and $u$ respectively; $E, \mathrm{EC}$, and $U$ are the language variables of $e, \mathrm{ec}$, and $u$ defined on its respective theory domains; and $D / F$ acts as fuzzy modules, whose functions are to convert the real determinate input into fuzzy vector. And $A^{*} \circ R$ module is the reasoning module. According to the input fuzzy vector and the fuzzy control rules, the fuzzy output $U$ is worked out according to the fuzzy reasoning synthesis rules. $F / D$ module is defined as clear modules, which is to convert the fuzzy quantity $U$ into clear amount, then to obtain the actual control amount and to act on the executing agency through quantitative factor.

In the design of the fuzzy control, the universe of language variables is usually defined as the discrete universe of 


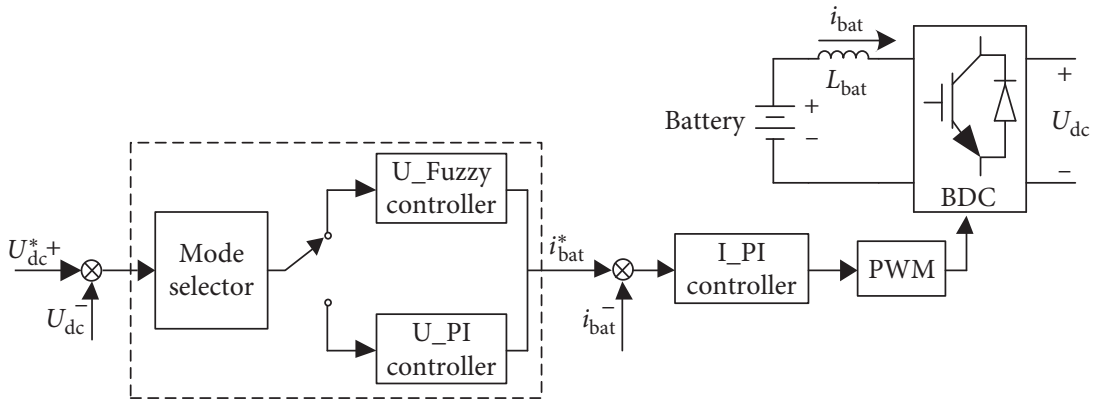

Figure 3: BDC controlling frame.

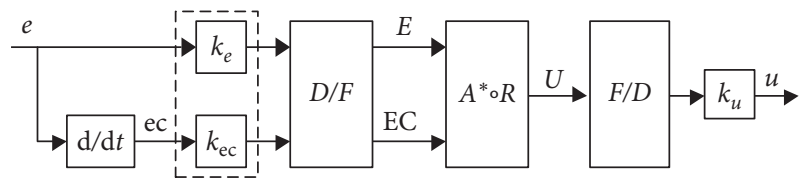

Figure 4: Fuzzy controller frame.

finite integers, and the input and output variables are transformed on dimension, so that they can fall within the scope of their respective universe. This paper regards the fuzzy universe of $E, \mathrm{EC}$, and $U$ as $N=[-5,5]$ and, according to the various sensitivity of the controlled objects to the input variables, sets the fuzzy subset of $E$ and $U$ as negative big (NB), negative medium (NM), negative small (NS), negative zero (NO), positive zero (PO), positive small (PS), positive medium (PM), and positive big $(\mathrm{PB})$ and sets the fuzzy subset as negative big (NB), negative small (NS), zero (ZO), positive small (PS), and positive big (PB). Reducing the number of ECfuzzy subset can reduce the number of subordinate functions in the reasoning module and can speed up the operation speed of fuzzy controller. Among them, the universe transformation schematic is shown in Figure 5, and subordinate functions of the input amount $E$, ECand the output amount $U$ are shown in Figures 6(a)-6(c).

The fuzzy reasoning rules of $U$ are presented in Table 1 in accordance with the control theory and experience. Taking $E=\mathrm{NB}$ and $\mathrm{EC}=\mathrm{NB}$ then $U=\mathrm{NB}$ as an example, it indicates that the current DC bus voltage is much larger than expected value, and the error is increasing continuously when the voltage deviation $e$ of the DC bus is $\mathrm{NB}$ and the deviation's change rate is negative big. Therefore, it is necessary to rapidly reduce the output $U$ of converters so that it operates in the Buck mode, absorbs redundant energy from the system, and maintains the stability of the bus voltage.

On the basis of the above fuzzy-control rules, the 3D effect diagram of input and output relationship of the fuzzy controller is shown in Figure 7.

3.2. Mode Selector. The mode selector is used to automatically switch the operating mode of the dual-mode controller, and it will calculate an error threshold based on the control blind field of the fuzzy controller. Hence, when the systematic deviation is greater than that of the threshold, the fuzzy controller is employed to render the controlled objects

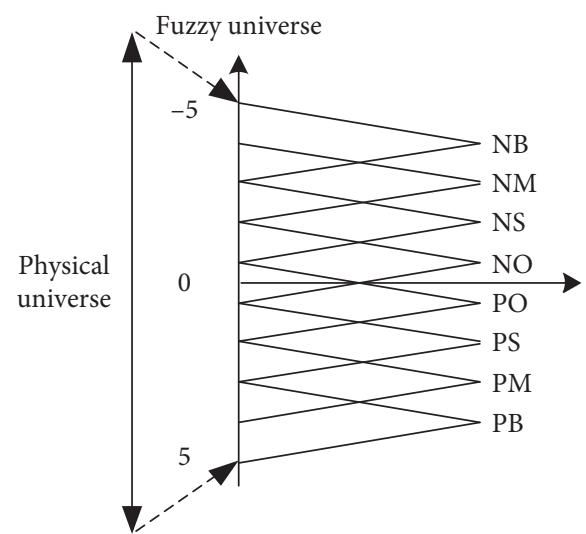

FIGURE 5: Universe transformation schematic diagram.

faster approaching the expected value to accelerate the dynamic response speed of the system. It is believed that the systematic adjustment accesses the adjust blind area of the fuzzy controller when systematic input error is less than that of the threshold. So, it automatically switches to the PI control mode, aiming at lowering the system's steady-state error and improving the system's controlling accuracy.

The fuzzy controller on the discrete universe has control blind area near the equilibrium points. Through setting the physical universe of systematic deviatione as $[-a, a](a>0)$, the fuzzy universe as $N_{j}=\left[-n_{j},-n_{j}+1, \ldots,-1,0,1, \ldots, n_{j}-\right.$ $\left.1, n_{j}\right]\left(n_{j}\right.$ is usually a positive integer from 3 to 7 ), and the quantitative factor as $k_{e}=n_{j} / a$ of $e$, it can be concluded that the corresponding fuzzy value of the systematic deviation is $n=k_{e} \times e$. If $n$ is an integer, it is the value in the fuzzy universe $N_{j}$. And the calculated $n$ is not an integer; the value of $n$ is worked out from the following formula:

$$
n= \begin{cases}n_{j}, & k_{e} \times e \geq n_{j}, \\ \operatorname{sgn}\left(k_{e} \times e\right) \operatorname{int}\left(\left|k_{e} \times e\right|+0.5\right), & -n_{j}<k_{e} \times e<n_{j}, \\ -n_{j}, & k_{e} \times e \leq-n_{j} .\end{cases}
$$

In the formula, the symbol operator "sgn" means plusminus sign of the value in the parenthesis. The integer operator "int" represents the integer part in the parenthesis behind the sign. For example, if there is $k_{e} \times e=-6.2, n=n_{j}=-6$. According to (3), if $n=0$ near the equilibrium points, the value of the system's deviation at this 


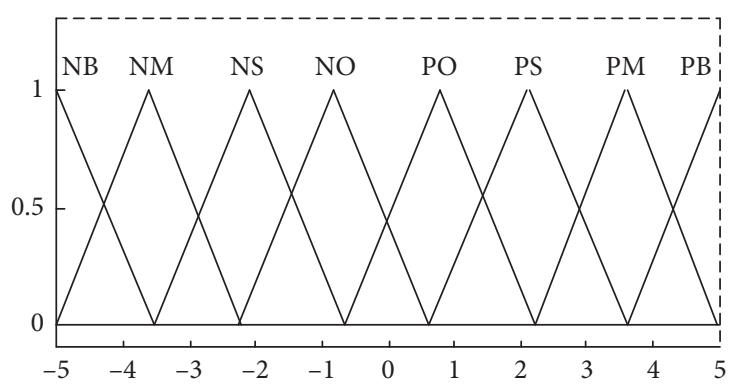

(a)

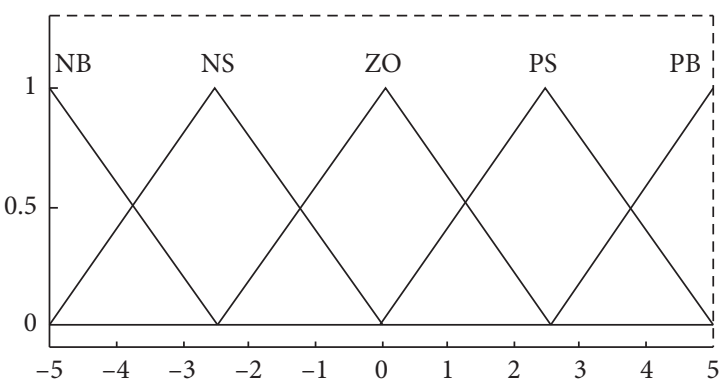

(b)

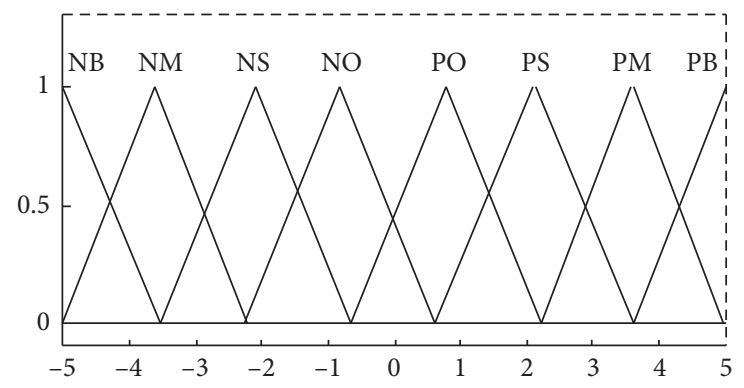

(c)

Figure 6: Relationship diagram of subordinate function. (a) Subordinate function of the input amount $E$, (b) subordinate function of the input amount EC, and (c) subordinate function of the output amount $U$.

TABLE 1: The table of fuzzy reasoning rules of $U$.

\begin{tabular}{lccccc}
\hline & & & $U$ & & \\
\hline EC/E & NB & NS & ZO & PS & PB \\
NB & NB & NB & NB & NM & NM \\
NM & NB & NM & NM & NM & NS \\
NS & NM & NS & NS & NS & NO \\
NO & NS & NO & NO & NO & PO \\
PO & NO & PO & PO & PO & PS \\
PS & PO & PS & PS & PS & PM \\
PM & PS & PM & PM & PM & PB \\
PB & PM & PB & PB & PB & PB \\
\hline
\end{tabular}

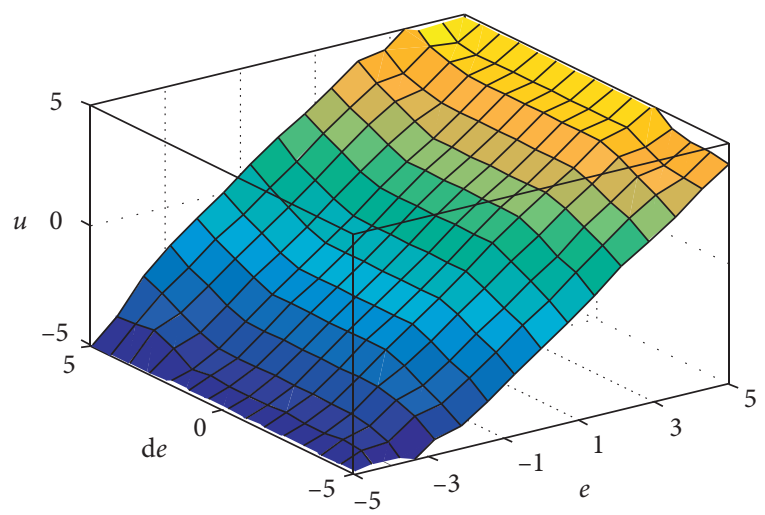

FIGURE 7: The input and output relationship figure of the fuzzy controller. time may not equal zero. There is a controlled blind area, and its critical value is

$$
|X|=\frac{0.5}{k_{e}}=\frac{0.5 a}{n_{j}} .
$$

When the deviation $e$ of the system satisfies $|e|<0.5 a / n_{j}$, the system enters into the blind area of the fuzzy controller, which is considered to have reached a steady state. Therefore, this deviation cannot be eliminated, seriously affecting the stable-state performance of the controlled system. As can be seen from formula (4), the larger $a$ is, the greater the critical value of the blind regions will be and the more the system's error of the steady state will be. And the larger $n_{j}$ is, the less the critical value of the blind area will be and the less the system's error of the steady state will be, while the system's calculation will increase at the same time. According to the size of the critical value of the fuzzy control blind area, the threshold is set, and generally the latter is greater than the former.

\section{Simulations and Experimental Results}

4.1. Simulations and Results. In the light of the circuit structure diagram of the photovoltaic DC microgrid shown in Figure 2, the simulation model is constructed in MATLAB/Simulink, as shown in Figure 8, and the systematic simulation parameters are shown in Table 2.

The expected value of the bus voltage is $650 \mathrm{~V}$, and the PV module Boost converters make use of tracking control mode (MPPT) at the maximum power point. And the Buck 


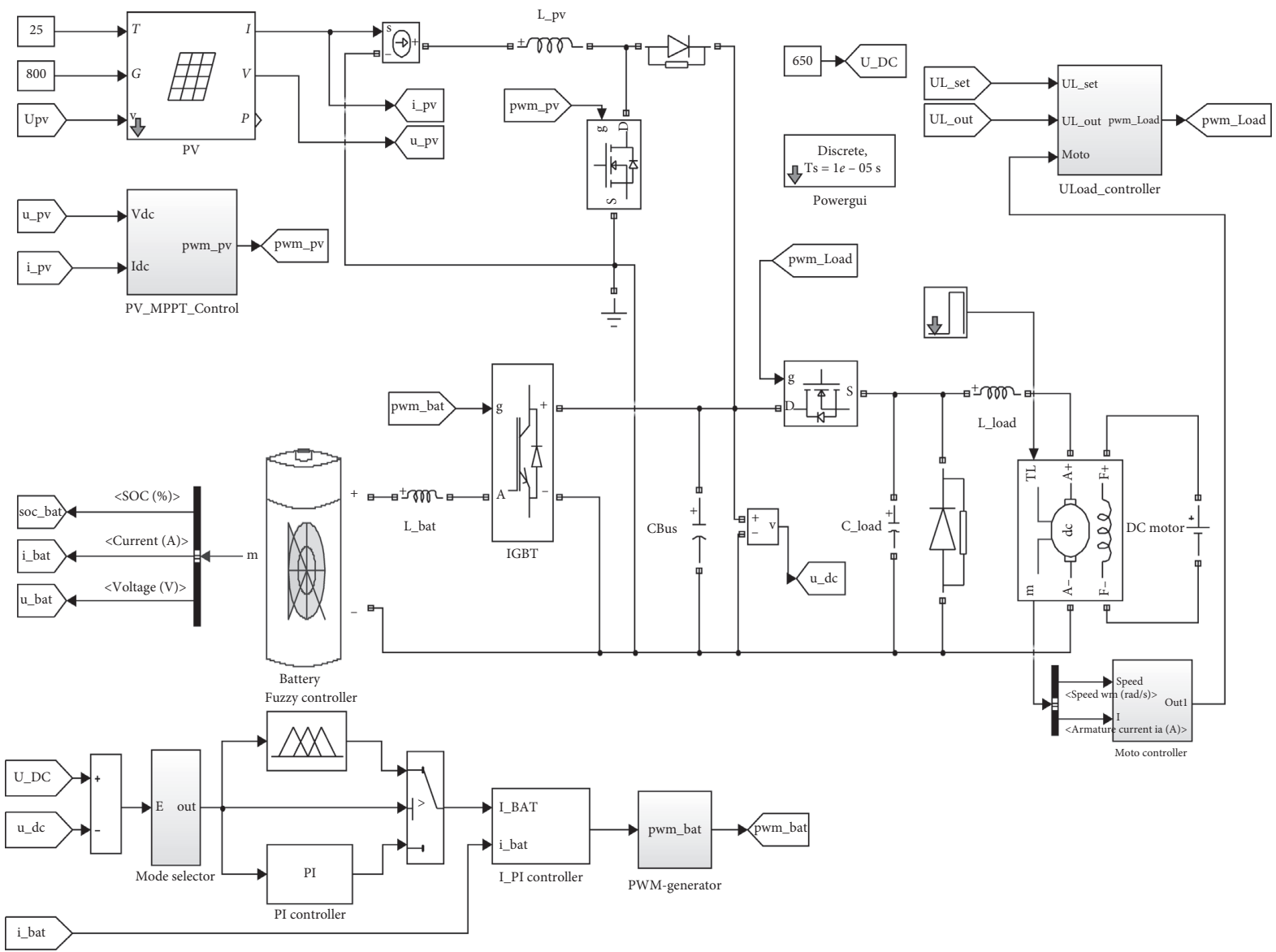

FiguRE 8: Simulation structure of the microgrid.

TABLe 2: Experimental parameters.

\begin{tabular}{lc}
\hline Parameter & Numerical value \\
\hline Output voltage of photovoltaic battery (V) & 12 \\
Capacitance of the DC bus (uF) & 1000 \\
Rated voltage of battery (V) & 12 \\
Rated capacitance of battery (Ah) & 38 \\
Rated power of DC motor (W) & 30 \\
Rated voltage of DC motor (V) & 24 \\
Rated current of DC motor (A) & 2.1
\end{tabular}

utilizes single closed-loop control of voltage to lower the bus voltage to the rating voltage of the load motor, in order to ensure the motor's properly working. The following studies are used to research three transient processes of the system's initial power-up, the surge, and reduction of the load. In addition, the outer ring of the energy storage converter voltage works on the system's ability to restrain the fluctuations ability and dynamic response performance under the PI control, fuzzy control, and fuzzy-PI dual-mode control.

The oscillogram of the DC bus voltage under different control strategies is shown in Figure 9. In order to more intuitively compare the control effects of the three control strategies in different transient processes, the three parts, initial power-up, load's surge, and load's plummet, are enlarged as shown in Figures 10-12, respectively.

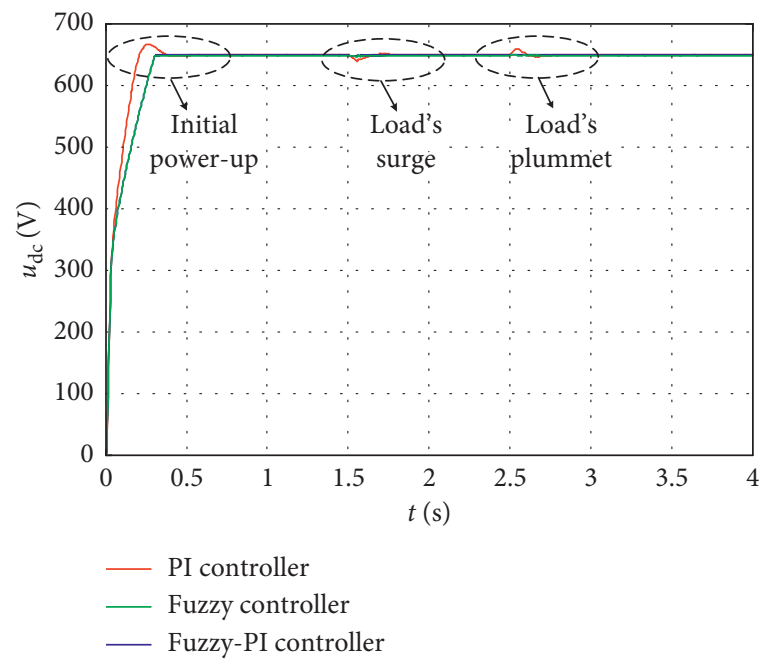

FIgURE 9: The comparison chart of the bus voltage.

The partial amplification chart of the DC bus voltage at the initial power-up is shown in Figure 10. As seen from Figure 10, when the voltage outer ring is controlled by the PI, the overshoot of the DC bus is $15.5 \mathrm{~V}$, stable at $650 \mathrm{~V}$ at about $0.5 \mathrm{~s}$, while the voltage outer ring is controlled by the fuzzy control, the DC bus voltage reaches stable at $0.3 \mathrm{~s}$, and there is no overshoot. But due to the existence of control 


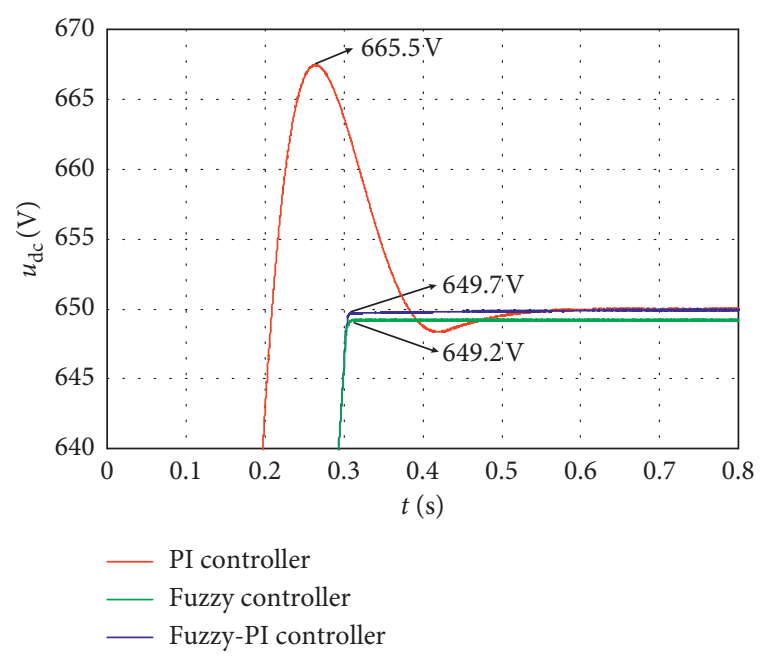

FIGURE 10: Initial power-up.

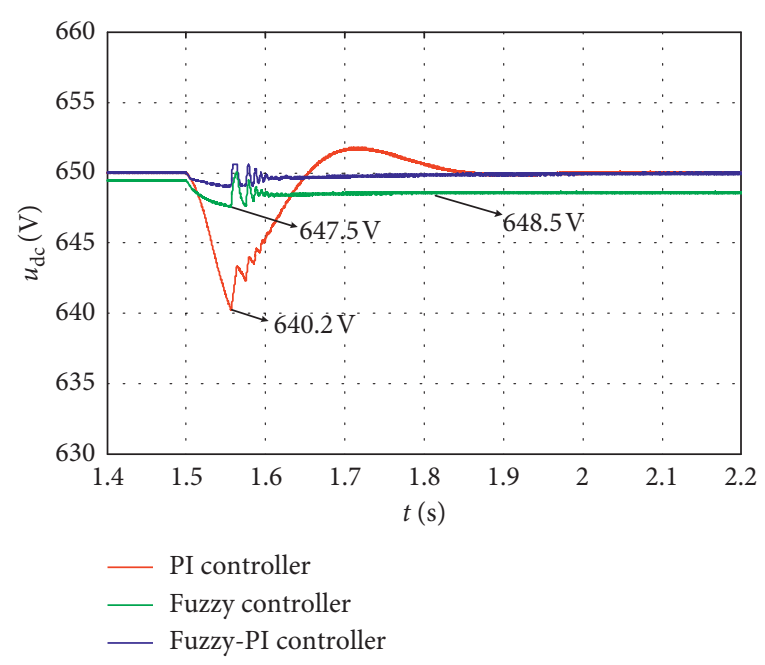

Figure 11: Load's surge. blind spots, the bus voltage is stable at $649.2 \mathrm{~V}$ and fails to achieve the expected value, and the system does not have the trend of farther adjustment, while the fuzzy-PI dual-mode controller using the fuzzy control is introduced; if the deviation of the bus voltage is large, the fuzzy control is used; if the deviation of the bus voltage is small, the PI control is adopted. On the basis of the figures above, due to the large voltage deviation of the bus, far greater than the threshold set by the mode selector, the control curves of the fuzzy control and fuzzy-PI dual-mode almost coincide, indicating that the fuzzy-PI dual-mode controller is operated in fuzzy control mode at this time. The bus voltage is $649.7 \mathrm{~V}$ at $0.3 \mathrm{~s}$, reaching a steady state. From the above analysis, it can be seen that in the process of electrical transient state on the system, the fuzzy-PI dual-mode control improves the dynamic response performance of the system compared with the PI control. And compared with the fuzzy control, the fuzzy-PI dual-mode control reduces the steady-state error of the system.

Figure 11 is the partial magnification of the DC bus voltage during the load's surge. As can be seen from the figure, at the $1.5 \mathrm{~s}$, the DC bus voltage under the PI control sharply drops, but it is stable at $650 \mathrm{~V}$ attachments at some $85 \mathrm{~s}$ with load power suddenly increasing, while in the recovery process there is an overshoot phenomenon. When adopting the fuzzy control, the load instantaneously elevates, the bus voltage reduces by $2.5 \mathrm{~V}$ and stabilizes at $650 \mathrm{~V}$ with $1.5 \mathrm{~V}$ steady-state error, and the system cannot be further adjusted. When using the fuzzy-PI dual-mode controller, the drop of the bus voltage is about $1 \mathrm{~V}$, reaching stability at $1.6 \mathrm{~s}$, gradually restoring to $650 \mathrm{~V}$, and having no overshoot and steady-state error.

Figure 12 is a partial enlarged one of the DC bus voltage when the load is suddenly reduced. The load suddenly reduces at $2.5 \mathrm{~s}$, the bus voltage uplifts $10 \mathrm{~V}$ under PI control, the overshoot phenomenon is presented in the recovery process, and the voltage is gradually stabilized to $650 \mathrm{~V}$ at about $2.9 \mathrm{~s}$. On employing the fuzzy controller, the bus voltage reaches the steady-state value of $649.2 \mathrm{~V}$ after oscillating adjustment. When employing the fuzzy-PI dual- mode controller, the voltage of the bus increases $1 \mathrm{~V}$ in the load's instantaneous reduction and recovers to about $650 \mathrm{~V}$ at $2.7 \mathrm{~s}$.

The above analysis shows that in the three different transient processes, systematic initial power-up, load's surge, and load's reduction, relative to PI control and fuzzy control, the fuzzy-PI dual-mode controller combines the advantages between the fuzzy control and the PI control, which is able to effectively restrain the large fluctuations and impact on improving the dynamic response at the same time and enhance the robustness of the system.

4.2. Experiments and Results. Taking the safety factors into account, the voltage level will be lowered for experiments, and the DSPACE 1104 control platform is used to further test the effectiveness of the proposed fuzzy-PI dual-mode controller in this paper. With designing the bus voltage level of $24 \mathrm{~V}$ of experimental platform, the photovoltaic simulator and battery connected to the input of the experimental board as the distributed power source and energy storage equipment of the system, and output of the experimental board is connected to the DC motor load, and the specific experimental parameters are shown in Table 2.

Figure 13 is the oscillogram for the DC bus voltage, similar to the simulation part. In studying the three different transient processes of the initial power-up, load's surge, and load's reduction of photovoltaic DC microgrid, the voltage outer ring utilizes the PI control, fuzzy control, and fuzzy-PI dual-mode controller to research the fluctuation situations of the bus voltage. Figures 14-16 are the oscillograms of the bus voltage for these processes.

As can be seen from Figures 14-16, in the three different transient processes of the initial power-up, load's surge, and sudden reduction, when using the fuzzy control, the voltage outer ring has steady-state errors and has no further adjusting trend. There is less steady-state errors, while the overshoot and weak dynamic performance exists under the PI control. Using the fuzzy-PI dual-mode controller can effectively lower the steady-state errors under the fuzzy 


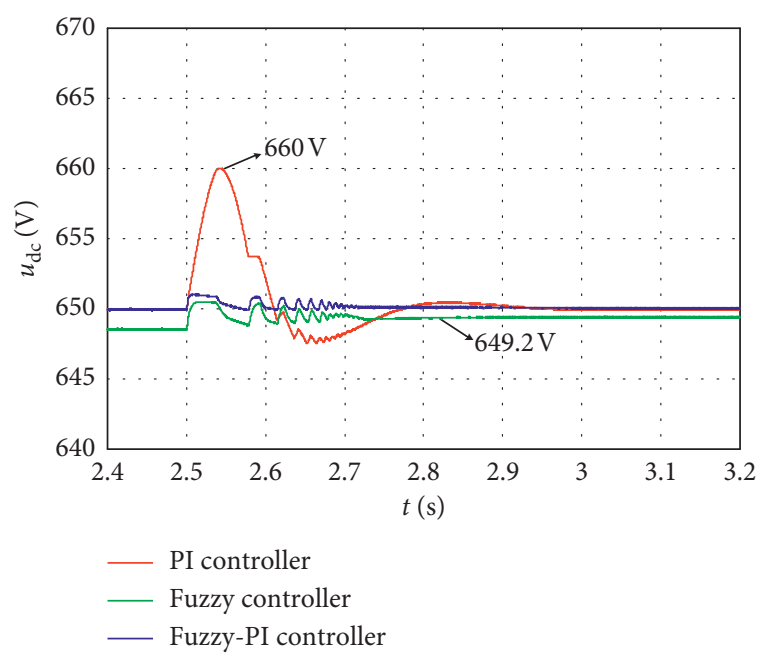

Figure 12: Load's plummet.

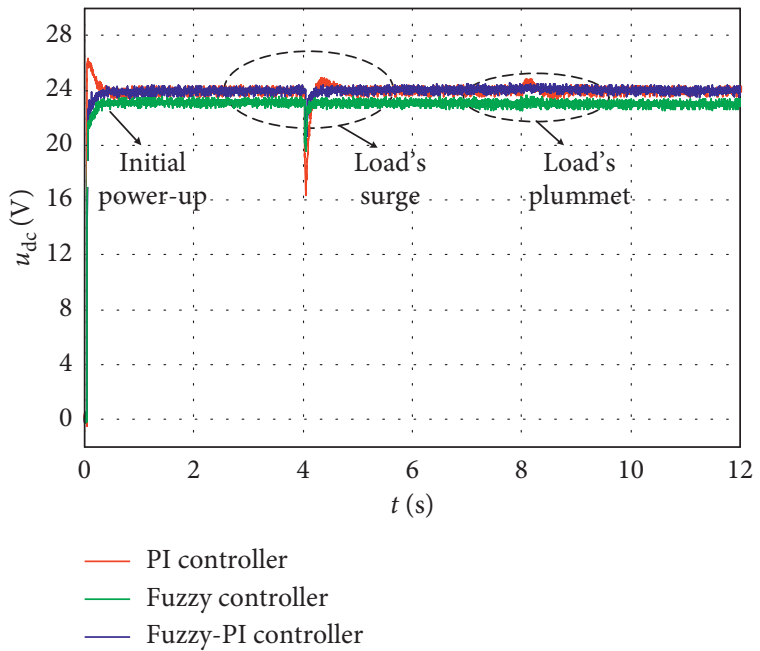

FIgURE 13: The oscillogram of the DC bus voltage.

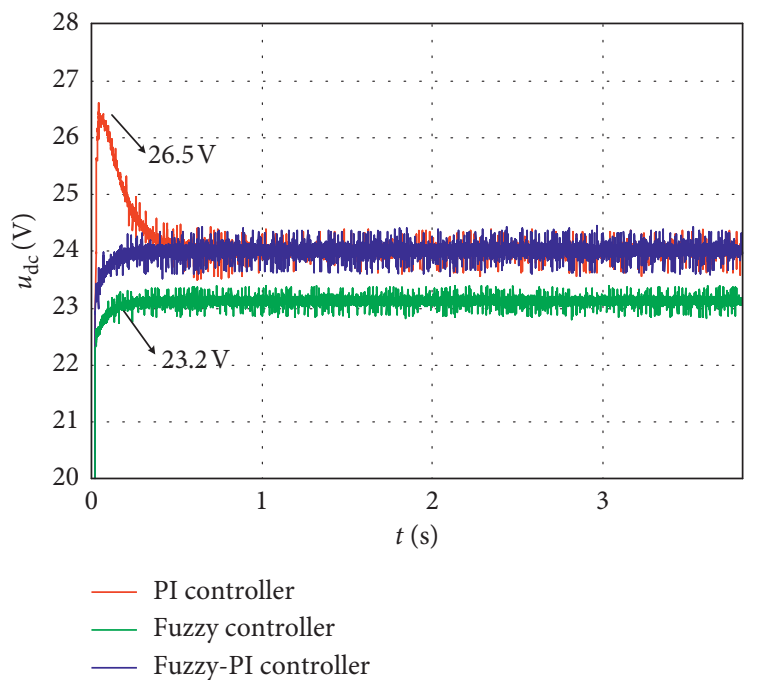

FIgURE 14: Initial power-up.

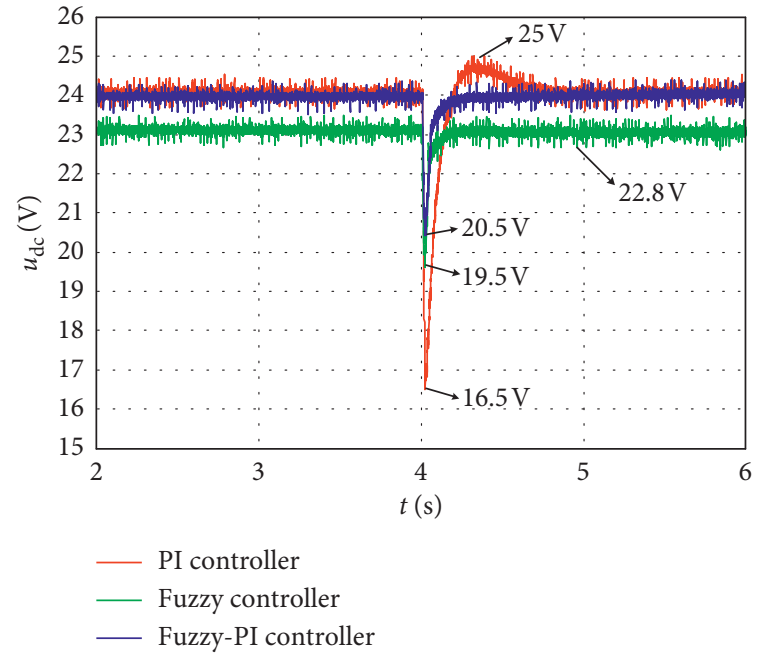

FIGURE 15: Load's surge.

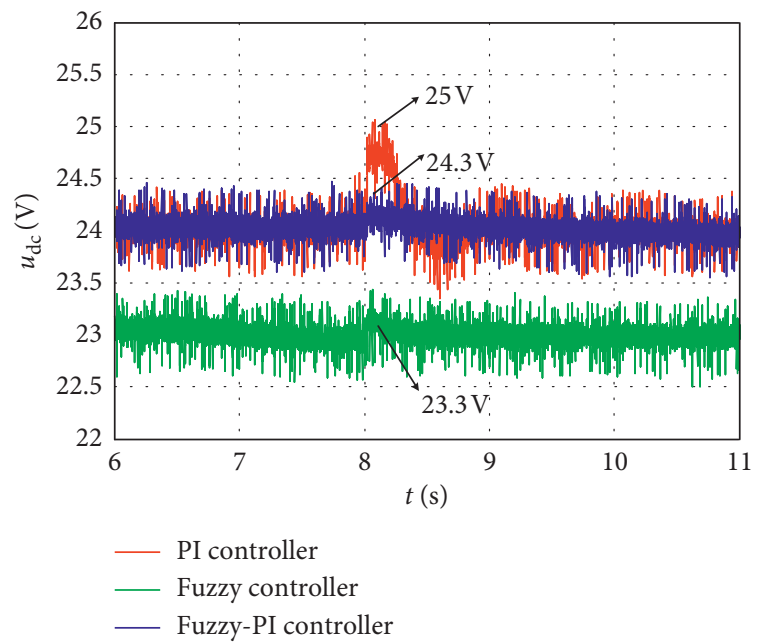

FIGURE 16: Load's plummet.

TABLE 3: Comparison of performance indexes under different controlling strategies.

\begin{tabular}{lcccc}
\hline & PI & $\begin{array}{c}\text { Fuzzy } \\
\text { controller }\end{array}$ & $\begin{array}{c}\text { Fuzzy-PI } \\
\text { controller } \\
\text { controller }\end{array}$ \\
\hline $\begin{array}{l}\text { Initial } \\
\text { power-up }\end{array}$ & $\begin{array}{c}\text { Adjustment } \\
\text { time (s) } \\
\text { Voltage } \\
\text { overshoot (V) } \\
\text { Steady-state } \\
\text { error (V) }\end{array}$ & 0.4 & 0.2 & 0.2 \\
& $\begin{array}{c}\text { Adjustment } \\
\text { time (s) }\end{array}$ & 0.8 & 0 & 0 \\
$\begin{array}{l}\text { Load's } \\
\text { surge }\end{array}$ & $\begin{array}{c}\text { Voltage } \\
\text { variation (V) } \\
\text { Steady-state } \\
\text { error (V) }\end{array}$ & 7.5 & 0.2 & 0.2 \\
\hline $\begin{array}{l}\text { Adjustment } \\
\text { time (s) } \\
\text { Load's }\end{array}$ & 0.8 & 0.2 & 3.5 \\
$\begin{array}{l}\text { Vharp } \\
\text { reduction } \\
\text { variation (V) } \\
\text { Steady-state } \\
\text { error (V) }\end{array}$ & 1 & 0 & 0.5 & 0.2 \\
\hline
\end{tabular}


control and improve the dynamic response performance under the PI control.

The results of the experiments mentioned above show that when the system is disturbed, the fuzzy-PI dual-mode controller can successfully enhance the adjusted speed and controlled accuracy of the system, meeting the requirements of rapid recovery of the DC bus voltage, better realizing the voltage stability of the DC bus. The specific performance indexes are shown in Table 3:

\section{Conclusion}

In terms of the problems of bus voltage stabilization in the photovoltaic DC microgrid, this paper adopts the fuzzy-PI dualmode controller to upgrade the traditional dual closed-loop control. For the voltage outer ring, according to the bus voltage deviation, functioning mode automatically switches. When the bus voltage deviation is large, the fuzzy controller is used to obtain good transient performance. When the bus voltage deviation is small, the PI controller is used to obtain good steadystate performance. The specific conclusions are as follows:

(1) Compared with the PI control and the fuzzy control, fuzzy-PI dual-mode controller combines the advantages of these two controllers, which can validly enhance the dynamic respond and restrain the fluctuation and impact of the DC bus voltage, so as to improve the robustness of the system

(2) The fuzzy controller in the discrete universe has controlling blind areas near the equilibrium points. The larger the theoretical material universe interval is, the greater the critical value of the blind areas is and the more the system's errors of the steady state are. The more elements in the fuzzy universe, the smaller the critical value of the blind areas is, and the less the steady-state error of the system is, which will lead to an increase in the system's calculation amount

(3) Simulation and experiments show that in the three different transient processes, including initial power-up, load's surge, and load's sudden reduction, the fuzzy-PI dual-mode controller control has flexible control, strong adaptability, and strong antijamming ability.

\section{Data Availability}

The data used to support the findings of this study have been deposited in the Figshare repository (https://figshare.com/ articles/simulation_and_experimental_data_xlsx/9563897).

\section{Conflicts of Interest}

The authors declare that there are no conflicts of interest regarding the publication of this paper.

\section{Acknowledgments}

This work was supported by the Natural Science Foundation of China (no. 51567002) and the Guangxi Natural Science Foundation (no. 2017GXNSFAA198161).

\section{References}

[1] Q. Yang, D. An, W. Yu, Z. Tan, and X. Yang, "Towards stochastic optimization-based electric vehicle penetration in a novel archipelago microgrid," Sensors, vol. 16, no. 6, p. 907, 2016.

[2] B. Li, S. Huang, and X. Chen, "Performance improvement for two-stage single-phase grid-connected converters using a fast DC bus control scheme and a novel synchronous frame current controller," Energies, vol. 10, no. 3, 2017.

[3] M. Yazdanian and A. Mehrizi-Sani, "Distributed control techniques in microgrids," IEEE Transactions on Smart Grid, vol. 5, no. 6, pp. 2901-2909, 2014.

[4] D. Xu, J. Liu, and X.-G. Yan, "A novel adaptive neural network constrained control for a multi-area interconnected power system with hybrid energy storage," IEEE Transactions on Industrial Electronics, vol. 65, no. 8, pp. 6625-6634, 2018.

[5] Z. Lei, F. Wang, Y. Gao, and Y. Ruan, "Research status and application analysis of bidirectional DC-DC converters in DC micro-grids," Transactions of China Electrotechnical Society, vol. 31, no. 22, pp. 137-147, 2016.

[6] C. Shuaixun, H. Beng Gooi, and M. Wang, "Sizing of energy storage for microgrids," IEEE Transactions on Smart Grid, vol. 3, no. 1, pp. 142-151, 2012.

[7] C. Wang, Y. Liu, X. Li, L. Guo, L. Qiao, and H. Lu, "Energy management system for stand-alone diesel-wind-biomass microgrid with energy storage system," Energy, vol. 97, pp. 90-104, 2016.

[8] C. Chen and S. Duan, "Optimal allocation of distributed generation and energy storage system in microgrids," IET Renewable Power Generation, vol. 8, no. 6, pp. 581-589, 2014.

[9] B. Zhao, Q. Yu, and W. Sun, "Extended-Phase-shift control of isolated bidirectional DC-DC converter for power distribution in microgrid," IEEE Transactions on Power Electronics, vol. 27, no. 11, pp. 4667-4680, 2012.

[10] M. Rana and L. Li, "An overview of distributed microgrid state estimation and control for smart grids," Sensors, vol. 15, no. 2, pp. 4302-4325, 2015.

[11] N. Korada and M. K. Mishra, "Grid adaptive power management strategy for an integrated microgrid with hybrid energy storage," IEEE Transactions on Industrial Electronics, vol. 64, no. 4, pp. 2884-2892, 2017.

[12] F. A. Inthamoussou, J. Pegueroles-Queralt, and F. D. Bianchi, "Control of a supercapacitor energy storage system for microgrid applications," IEEE Transactions on Energy Conversion, vol. 28, no. 3, pp. 690-697, 2013.

[13] C. He, G. Hu, F. L. Lewis, and A. Davoudi, "A distributed feedforward approach to cooperative control of AC microgrids," IEEE Transactions on Power Systems, vol. 31, no. 5, pp. 4057-4067, 2016.

[14] X. Li, L. Guo, S. Zhang, C. Wang, and Y. W. Li, "Observerbased DC voltage droop and current feed-forward control of a DC microgrid," IEEE Transactions on Smart Grid, vol. 99, p. 1, 2017.

[15] D. Takei, H. Fujimoto, and Y. Hori, "Load current feedforward control of boost converter for downsizing the output filter capacitor," in Proceedings of the 40th Annual Conference of the IEEE Industrial Electronics Society, IEEE, Dallas, TX, USA, October 2014.

[16] N. Hou, W. Song, and W. U. Mingyi, "A load current feedforward control scheme of dual active bridge DC/DC converters," in Proceedings of the Chinese Society for Electrical Engineering, pp. 2478-2485, Shanghai, China, November 2016. 
[17] W. Lu, N. Zhao, S. Lang, S. Liu, and L. Zhou, "Nonlinear control of a DC/DC buck converter and its ripple compensation strategy," in Proceedings of the Chinese Society for Electrical Engineering, pp. 35-46, Shanghai, China, August 2013.

[18] Y. Li, Q. Sun, D. Wang, and S. Lin, “A virtual inertia-based power feedforward control strategy for an energy router in a direct current microgrid application," Energies, vol. 12, no. 3, 2019.

[19] L. Zhi-Lin, W. Q. Tang, and X. J. Zeng, "Voltage stability control of isolated DC micro-grid based on power feed forward," Power Electronics, vol. 49, no. 8, pp. 32-36, 2015.

[20] P. Song and W. Zhu, "Virtual direct power control strategy of dual active bridge DC-DC converter," Electrical Measurement \& Instrumentation, vol. 55, no. 5, pp. 125-131, 2018.

[21] O. Ibrahim, N. Z. Yahaya, N. Saad, and K. Y. Ahmed, "Development of observer state output feedback for phase-shifted full bridge DC-DC converter control," IEEE Access, vol. 99, p. 1, 2017

[22] W. Chengshan, L. Xianlin, G. Li, and Y. W. Li, "A nonlineardisturbance-observer-based DC-bus voltage control for a hybrid AC/DC microgrid," IEEE Transactions on Power Electronics, vol. 29, no. 11, pp. 6162-6177, 2014.

[23] L. Benadero, R. Cristiano, D. J. Pagano, and E. Ponce, "Nonlinear analysis of interconnected power converters: a case study," IEEE Journal on Emerging and Selected Topics in Circuits and Systems, vol. 5, no. 3, pp. 326-335, 2015.

[24] G. Sun and Z. Ma, "Practical tracking control of linear motor with adaptive fractional order terminal sliding mode control," IEEE/ASME Transactions on Mechatronics, vol. 22, no. 6, pp. 2643-2653, 2017.

[25] Y. Yin, J. Liu, J. A. Sanchez et al., “Observer-based adaptive sliding mode control of NPC converters: an rbf neural network approach," IEEE Transactions on Power Electronics, vol. 34, no. 4, pp. 3831-3841, 2019.

[26] Y. Gao, F. Xiao, J. Liu, and R. Wang, "Distributed soft fault detection for interval type-2 fuzzy-model-based stochastic systems with wireless sensor networks," IEEE Transactions on Industrial Informatics, vol. 15, no. 1, pp. 334-347, 2019.

[27] Z. Zhu, Z. Zhao, H. Cui, and F. Shi, "Improved T-S fuzzy control for uncertain time-delay coronary artery system," Complexity, vol. 473, pp. 227-238, 2019. 